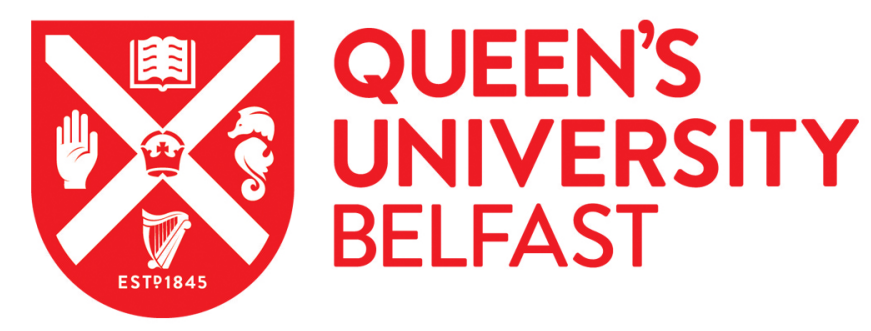

\title{
Source organic matter analysis of saltmarsh sediments using SIAR and its application in relative sea-level studies in regions of C4 plant invasion
}

Craven, K. F., Edwards, R. J., \& Flood, R. P. (2017). Source organic matter analysis of saltmarsh sediments using SIAR and its application in relative sea-level studies in regions of C4 plant invasion. Boreas, 46(4), 642654. https://doi.org/10.1111/bor.12245

Published in:

Boreas

Document Version:

Peer reviewed version

Queen's University Belfast - Research Portal:

Link to publication record in Queen's University Belfast Research Portal

\section{Publisher rights}

(C) 2017 Collegium Boreas. Published by John Wiley \& Sons Ltd.

This work is made available online in accordance with the publisher's policies. Please refer to any applicable terms of use of the publisher.

\section{General rights}

Copyright for the publications made accessible via the Queen's University Belfast Research Portal is retained by the author(s) and / or other copyright owners and it is a condition of accessing these publications that users recognise and abide by the legal requirements associated with these rights.

Take down policy

The Research Portal is Queen's institutional repository that provides access to Queen's research output. Every effort has been made to ensure that content in the Research Portal does not infringe any person's rights, or applicable UK laws. If you discover content in the Research Portal that you believe breaches copyright or violates any law, please contact openaccess@qub.ac.uk. 


\section{BOREAS}

\section{Source organic matter analysis of saltmarsh sediments using SIAR and its application in relative sea-level studies in regions of C4 plant invasion}

\begin{tabular}{|r|l|}
\hline Journal: & BOREAS \\
\hline Manuscript ID & Draft \\
\hline Manuscript Type: & Original Article \\
\hline Date Submitted by the Author: & n/a \\
\hline Complete List of Authors: & $\begin{array}{l}\text { Craven, Kieran; National University of Ireland Maynooth, Geography } \\
\text { Edwards, Robin; Trinity College Dublin School of Natural Science, } \\
\text { Geography } \\
\text { Flood, Rory; Trinity College Dublin School of Natural Science }\end{array}$ \\
\hline Keywords: & Relative \\
\hline & \\
\hline
\end{tabular}

SCHOLARONE ${ }^{m}$

Manuscripts 


\title{
Source organic matter analysis of saltmarsh sediments using SIAR and its application in relative sea-level studies in regions of $\mathrm{C}_{4}$ plant invasion
}

\author{
Authors: Kieran F Craven, Robin J Edwards, Rory P Flood
}

Relative sea-level (RSL) reconstructions in Western Europe utilising sediment geochemistry methodologies are hindered by the absence of modern analogues due to the introduction of $\mathrm{C}_{4}$ plants into previously $\mathrm{C}_{3}$-dominated coastal environments. Mixing models of source carbon can alleviate this by characterising source contribution and identifying $\mathrm{C}_{4}$ input. Bayesian mixing models have advantages over traditional mixing models used in sediment biogeochemistry (based on simultaneous equations and generating unique solutions) as they are based on a transparent statistical paradigm and can incorporate both source variability and additional fractionation to quantify ranges of relative contributions from multiple sources. This study tests the application of one of these models (SIAR - Stable Isotope Analysis in R) in a biogeochemical context. Simulated data was used to test the underlying assumptions of SIAR and the model was found to accurately predict source input. When SIAR was applied to disparate saltmarsh sediments, Corg contributions of plant organic matter was found to increase with altitude within the tidal frame at the expense of particulate organic matter, in keeping with model framework predictions. $\delta^{13} \mathrm{C}$ varied by $4.4 \%$ in the inner estuary, and 9.4\%o in the outer. Removal of $\mathrm{C}_{4}$ source input indicated Holocene saltmarsh $\delta^{13} \mathrm{C}$ gradients varying from $0.5 \%$ and $2.4 \%$ in the inner and outer estuary respectively; a significant reduction, but still of use in RSL reconstruction studies. SIAR's application is not restricted to biogeochemical studies and should be suitable for a wide range of geochemical studies where traditional mass balance mixing models have been applied.

Keywords: RSL; Geochemistry; Organic carbon; Sediment; Mixing Models.

K.F. Craven, kieran.craven@ nuim.ie, Trinity College Dublin, School of Natural Sciences, Trinity College Dublin, Dublin 2. Ireland

Current address: Maynooth University. Department of Geography, Maynooth University, Maynooth, Co. Kildare. Ireland

R.J. Edwards, robin.edwards@tcd.ie, Trinity College Dublin, School of Natural Sciences, Trinity College Dublin, Dublin 2. Ireland

R.P. Flood, rpflood@tcd.ie, Trinity College Dublin, School of Natural Sciences, Trinity College Dublin, Dublin 2. Ireland 
Relative sea levels around the UK and Ireland have fluctuated primarily as a response to the presence of the former British-Irish Ice Sheet (BIIS) (Bradley et al. 2009; Bradley et al. 2011). The interaction between this regional ice mass and the rising sea-levels caused by the subsequent melting of global ice masses has produced complex relative sea-level histories that vary spatially and are captured in the sedimentary record (e.g. Edwards et al. 2004; Brooks et al. 2008; Barlow et al. 2014). Evidence for acceleration in the rate of global sealevel rise over the last 100-200 years has generated considerable interest in recent years with records from tide gauges showing a global eustatic sea-level rise of 1.7-1.8mm yr ${ }^{-1}$ (Bindoff et al. 2007; Church \& White 2011), while regional sediment-based reconstructions exhibit fluctuating changes of up to $4.2 \mathrm{~mm} \mathrm{yr}^{-1}$ (Gehrels et al. 2012). These contrast with lower rates of sea-level rise from the mid to late-Holocene (e.g. Kemp et al. 2011). Relative sea-level (RSL) reconstruction allows the development of a context for understanding and predicting future changes.

In recent years researchers have developed RSL reconstruction techniques that use sediment geochemistry to assign indicative meaning to sediments in both C4 (Emery et al. 1967;

Törnqvist et al. 2004; Kemp et al. 2010) and C3 dominated regions (Andrews et al. 2000; Mackie et al. 2005; Wilson et al. 2005a, 2005b; Khan et al. 2015). However, C3 dominated reconstructions, particularly in Western Europe, remain problematic due to the lack of suitable modern analogues resulting from the widespread contemporary distribution of the $\mathrm{C}_{4}$ plant Spartina spp. in the intertidal low marsh zone. To avoid this issue, recent studies have 
relied on local modern analogues, restricted to where Spartina spp. is absent (Khan et al. 2015); this limits their applicability.

Mixing models of source organic carbon may help solve this restriction. Mixing models have been widely used in biogeochemical studies to estimate relative contributions of organic inputs into terrestrial, lacustrine, estuarine and marine systems for the past three decades (Schultz \& Calder 1976; e.g. Craft et al. 1988; Gordon \& Goñi 2003; Liu \& Kao 2007; Yu et al. 2010). Originally based on the relative proportions of isotopes (Schultz \& Calder 1976), their use has been extended to include other variables that are capable of recording mixing such as $\mathrm{C} / \mathrm{N},{ }^{14} \mathrm{C}$ and lignin-derived phenols (see Perdue \& Koprivnjak 2007 for an overview).

Previously applied ternary mixing models, in sediment biogeochemical studies (Goñi et al. 2003; Gordon \& Goñi 2003; Liu \& Kao 2007) remain hindered by end-member selection comprising of unique values. The calculations used to generate unique solutions to these mixing models are unable to incorporate source variation or diagenetic fractionation, even though these are acknowledged as inherently occurring in natural systems (e.g. Benner et al. 1991; Fogel \& Tuross 1999; Vane et al. 2006; Lamb et al. 2007). The mass balance equations of these models assume that the mixed sample value falls within the mixing polygon defined by connecting the sources on a bivariate plot. Should the sample fall outside of these bounds due to 1) omitting an important source value, 2) heterogeneity in the source or sample, 3) variability of fractionation between source and sample (e.g. diagenesis) then erroneous source 
fractional contributions will be calculated. Even if samples fall within the bounds of this plot, calculations can be erroneous for the very same reasons and so the unique solutions provided by the models should always be viewed as point estimates. In particular, the necessity to provide a unique geochemical value for a known heterogeneous source is a particular hindrance in these calculations.

Within the field of ecology, there has been rapid development of computational packages such as IsoSource, IsotopeR, SISUS, MixSIR and SIAR to solve mixing models using stable isotopes as system tracers and these are widely used in the characterisation of food webs with each package having its own benefits and limitations (see Phillips \& Gregg 2001; Phillips et al. 2005; Jackson et al. 2009; Erhardt 2010; Parnell et al. 2010; Hopkins \& Ferguson 2012). These Bayesian mixing models have advantages over traditional mixing models used in sediment biogeochemistry (based on simultaneous equations and generating unique solutions) as they are based on a transparent statistical paradigm and can incorporate both source variability and additional fractionation to quantify ranges of relative contributions from multiple sources.

This paper applies one of these statistical packages (SIAR) in a biogeochemical context to calculate organic source input to two modern saltmarshes using $\delta^{13} \mathrm{C}$ and $\mathrm{C} / \mathrm{N}$ as system tracers. The saltmarshes were selected based on the presence of endemic $\mathrm{C}_{3}$ plants and differing relative proportion of the invasive $\mathrm{C}_{4}$ plant Spartina anglica. This varied $\mathrm{C}_{\mathrm{org}}$ input at both sites will result in mixing of the two commonly analysed stable isotopes of carbon and 
nitrogen. While $\delta^{13} \mathrm{C}$ is considered relatively conservative and not susceptible to large diagenetic fractionation in sediment, $\delta^{15} \mathrm{~N}$ is rapidly altered during early diagenesis (e.g. Benner et al. 1991) and is unlikely to be an appropriate SIAR system tracer unless diagenetic fractionation is quantified. In its place, the absolute ratio of $\mathrm{C} / \mathrm{N}$ can be used (e.g. Goñi et al. 2003; Gordon \& Goñi 2003; Liu \& Kao 2007). The fractional contribution of the $\mathrm{C}_{4}$ component is then modelled and removed to provide a "pre-Spartina" signal that would be useful for Holocene habitat reconstruction and RSL reconstruction. To do this, it first uses simulated data to test the novel use of the absolute ratio $\mathrm{C} / \mathrm{N}$ as a system tracer for SIAR and as a comparison against the traditional methodology.

\section{SIAR}

SIAR (Stable Isotope Analysis in R), one of the more recently-developed packages, has the ability to include source variation and subsequent fractionation (e.g. trophic enrichment or diagenesis) within calculations and is therefore a significant advance on the ternary mixing models thus far utilised in biogeochemical studies. By modelling all feasible mixing solutions, and selecting those that best match the mixture composition, SIAR can include larger numbers of sources and quantify the range of source contribution. Using Monte Carlo methods and Bayesian statistics, SIAR provides estimates of error for its solutions as a probability distribution, thus making available information on precision of model outputs (Parnell et al. 2010). SIAR uses the statistical package R (Team 2011) to conduct calculations 
and both are freely available from the Comprehensive R Archive Network (CRAN) site - http://cran.r-project.org.

As most organic sources to natural systems are heterogeneous, and frequently experience post-depositional fractionation, SIAR provides potential for increased confidence in interpreting mixing solutions by incorporating error propagation in analysis; only selecting unique values for these sources, as traditional mixing models do, can result in significant error in fractional contribution calculation. Additionally, the ability to identify multiple sources, using only limited system tracers is a major advantage (Phillips 2001; Phillips \& Gregg 2003). These factors of SIAR mark significant improvements on traditional mixing models and could lead to its widespread and routine application in geochemical studies, including RSL reconstruction. Including error in calculations, it should be possible to remove the recent $\mathrm{C}_{4}$ signal from saltmarsh environments and model geochemical gradients during the Holocene.

There are limits to the application of SIAR and the main model assumptions include that (from Parnell et al. 2010): 1) there is no preferential uptake of isotopes; 2) variation associated with sources, and any fractionation, is normally distributed; 3 ) the generation of probable rather than unique solutions, even when high precision contributions are indicated; 4) SIAR will always fit a model, even if sources lie outside the mixing polygon. These caveats apply equally to $\mathrm{C} / \mathrm{N}$. 
While absolute ratios have not previously been used as system tracers for SIAR, their partitioning within a mixed sediment sample should be similar to stable isotopes and they have been used previously in traditional mixing models (Perdue \& Koprivnjak 2007).

\section{Simulated data}

Simulated data can test the performance of statistical models, and thus give insight on their underlying assumptions, as model predictions of key parameters can be compared with the specified values set before model initiation. SIAR was designed for use with stable isotopes and is underpinned by the following equation for its isotopic system tracers:

$\delta_{M}=f_{1} \delta_{1}+f_{2} \delta_{2} \mathrm{~L} f_{i} \delta_{i}+\mathrm{e}$

Where $\delta_{M}$ is the isotopic signature of the mixture, $f_{i}$ is the proportional contribution of the $i^{\text {th }}$ source to the mixture, $\delta i$ is the isotopic signature of the $i^{\text {th }}$ source and e is residual variation $\left(\sim \mathrm{N}\left[0, \mathrm{~s}^{2}\right]\right)$. Within ecological applications of SIAR, $\delta_{\mathrm{m}}$ is usually multi-dimensional, $\delta_{\mathrm{i}}$ is given its own normal distribution, and fractionation is allowed.

This is the same for a mixed sample using elemental ratios:

$$
A / B_{M}=f_{1} A / B_{1}+f_{2} A / B_{2}\left\llcorner f_{i} A / B_{i}+\mathrm{e}\right.
$$

Where $\mathrm{A} / \mathrm{B}_{M}$ is the elemental ratios of the mixture, $f_{i}$ is the proportional contribution of the $i$ th source to the mixture, $\mathrm{A} / \mathrm{B}_{i}$ is the elemental ratio of the $i$ th source and e is residual variation $\left(\sim \mathrm{N}\left[0, \mathrm{~s}^{2}\right]\right)$. This mixing equation (without the residual variation) has been used previously in 
biogeochemical studies alongside an isotopic tracer (e.g. Gordon \& Goñi 2003; Liu \& Kao 2007).

It is important to note that whenever a ratio of a variable (be it a relative ratio $\left[\delta^{13} \mathrm{C}\right]$, or an absolute one $[\mathrm{C} / \mathrm{N}])$ is used in linear mixing models, the mixed fraction returned is based on the denominator of the ratio (Perdue \& Koprivnjak 2007). Thus for $\delta^{13} \mathrm{C}$ (equivalent to ${ }^{13} \mathrm{C} /{ }^{12} \mathrm{C}$ ), linear mixing estimates the fractional contribution of ${ }^{12} \mathrm{C}$ from the sources, while for $\mathrm{C} / \mathrm{N}$, it is the contribution of nitrogen that is estimated. For mixing models to produce accurate solutions, the two system tracers must be recording the same fractional contributions; thus $\delta^{13} \mathrm{C}$ can be used alongside N/C ratios as they both estimate the fractional contribution of carbon (as ${ }^{12} \mathrm{C}$ comprises $98.9 \%$ of all carbon it provides a realistic estimation of Corg contributions); these are distinct from calculating organic matter fractions. While N/C ratios are used in the SIAR calculation, $\mathrm{C} / \mathrm{N}$ is used in the text, tables and figures and as this is more commonly referenced in the literature.

\section{Approximate position of Table 1}

For this simulation, three source $\delta^{13} \mathrm{C}$ and $\mathrm{C} / \mathrm{N}$ values (with inclusion of error; outlined in Table 1) were designated that are similar to published compositional values of saltmarsh $\mathrm{C}_{\text {org }}$ sources (e.g. Chmura et al. 1987; Wilson et al. 2005b; Kemp et al. 2010; Yu et al. 2010). Twenty specific values for each of the three sources were then randomly generated within this predetermined variation. These were mixed in randomised proportions to simulate mixed sediment with known $\mathrm{C}_{\text {org }}$ source proportion and are illustrated in Figure 1a. To determine 


\begin{abstract}
source contribution, SIAR v4.2 was run with these mixed simulated and source values over 500,000 iterations with the Markov Chain Monte Carlo algorithm (siarsolomcmcv4) and 50,000 burn-in, using R v3.2.3. The modal values of modelled scenarios, with $68 \%$ credibility intervals, reflective of conventional reporting of \pm 1 s.d., are presented alongside the known simulated values in Figure 1b. Source contribution calculated via traditional ternary end-member methods following the methodology of Liu and Kao (2007) are also included
\end{abstract}

\title{
Approximate position of Figure 1
}

With accurate source system tracer parameters, SIAR $68 \%$ credibility intervals include the

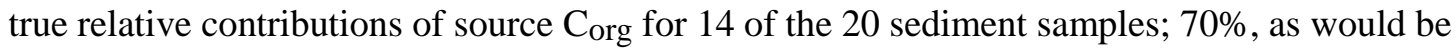
expected. Given this acceptable prediction of source contributions, the assumptions of SIAR for relative ratios of stable isotopes hold true for the absolute ratio of $\mathrm{C} / \mathrm{N}$, and so this ratio can be used in SIAR as a system tracer alongside $\delta^{13} \mathrm{C}$ to identify source $\mathrm{C}_{\text {org }}$ contribution to mixed sediments. While traditional methods do calculate source contribution, accuracy in these calculations varies greatly and cannot be predicted. While increasing the credibility interval of SIAR calculations would enhance inclusion of true mixed contribution, this is not possible using traditional mixing models and no estimation on precision can be determined. This is a major advantage SIAR has over existing traditional methods. 


\section{Saltmarsh data}

\section{Site Selection}

As SIAR can predict relative source proportions of simulated data, it can be applied empirically. For this the two spatially distributed Shannon estuary saltmarsh sites of Ringmoylan (RMN) and Querrin $(\mathrm{QN})$ in Ireland were selected for analysis of $\mathrm{C}_{\text {org }}$ contribution (Figure 2). The Shannon region is subsiding (Brooks et al. 2008) and saltmarshes in this area are minerogenic and exhibit contrasting vertical floral zonation (Craven 2013). Therefore, the three main Corg sources to these marshes would be particulate organic matter (POM) suspended in estuarine water (composed primarily of phytoplankton, with some plant detritus), $\mathrm{C}_{3}$ plant input, and $\mathrm{C}_{4}$ plant input. Due to tidal flooding, plant $\mathrm{C}_{\text {org }}$ deposition is expected to increase with altitude at the expense of POM (Lamb et al. 2006). Thus, vertical mixing of $\mathrm{C}_{\text {org }}$ contributions occurs as a function of altitude across a saltmarsh, controlled by altitude within the tidal frame. Given these relatively few source inputs and generally well-accepted vertical mixing (Wilson et al. 2005b; Lamb et al. 2006) that occurs on subsiding marshes, these should provide good test sites for the application of SIAR.

Native $\mathrm{C}_{3}$ plants such as Festuca rubra, Glaux maritima and Scirpus maritimus comprise the high marshes at both sites. The non-native $\mathrm{C}_{4}$ plant Spartina anglica, that now dominates low marsh environments in Ireland, is well established at QN, but not at RMN where the low marsh is greatly reduced with only a few isolated swards present. 


\section{Approximate position of Figure 2}

\section{Data Collection}

Bulk sediment samples of approximately $20 \mathrm{~cm}^{3}$ were recovered from the top $1 \mathrm{~cm}$ along transects extending from vegetated supratidal (above highest astronomical tide (HAT)), to unvegetated intertidal environments below mean high water neap tide (MHWNT) and mean tide level (MTL).

To investigate variation in $\mathrm{C}$ org source contribution, plant specimen and water samples were collected along the length of the Shannon estuary. The dominant plant species were collected from ten saltmarshes (Figure 2) and water samples, providing compositional POM values, were collected from six locations to include the range of water conditions found. Water samples were taken from successive high and low tides in August 2009, April 2010 and June 2010 to include temporal variation.

On return from the field, all sediment samples and organic sources were prepared and analysed via isotope ratio mass spectrometry (IRMS) to determine stable isotope values and elemental ratios. Sediment samples were dried at $40^{\circ} \mathrm{C}$ for 48 hours before being ground to a fine powder using a pestle and mortar. Samples were acid-rinsed via the method outlined in Craven et al. (2013) using 0.5 M HCl to remove inorganic carbon (IC) and rinsed in deionised water before being dried, ground and analysed. Plant samples were rinsed with deionised water, freeze dried and ground to a fine powder prior to analysis. Water samples were converted to $0.5 \mathrm{M} \mathrm{HCl}$ solutions and left overnight to remove IC. Samples were 
filtered using a vacuum pump onto pre-combusted Whatman glass fibre filter paper, rinsed with deionised water and dried at $50^{\circ} \mathrm{C}$. Organic material was then placed into tin capsules and analysed.

$\delta^{13} \mathrm{C}, \delta^{15} \mathrm{~N}, \% \mathrm{C}$ and $\% \mathrm{~N}$ of samples were analysed in a Flash 1112 series Elemental Analyser (EA) coupled to a Thermo Delta plus continuous flow mass spectrometer. The software package Eager-300 (Thermo Scientific) was used for performing on-line data acquisition and integration. Samples were analysed in tandem with both internal and international standards, with a standard:sample ratio of approximately 1:5. Precision of isotopic analysis was $<0.1 \%$ for both $\delta^{13} \mathrm{C}$ and $\delta^{15} \mathrm{~N}$. An internal standard $\left(\mathrm{C}_{\text {tot }}\right.$ and $\mathrm{N}_{\text {tot }}$ concentrations of $40.44 \%$ and $15.73 \%$ respectively) was used to ascertain elemental concentrations with a precision of less than $0.9 \%$ for $\mathrm{N}_{\text {tot }}$ and $0.6 \%$ for $\mathrm{C}_{\text {tot. }} \mathrm{C} / \mathrm{N}$ is reported as wt. $\%$ and not molar weight ratio in keeping with most sea-level studies (see Lamb et al. 2006).

\section{Results}

All recorded organic matter sources within the Shannon estuary were observed to be heterogeneous for both $\delta^{13} \mathrm{C}$ and $\mathrm{C} / \mathrm{N}$. Plants exhibit both inter- and intra-marsh isotopic and elemental variability (Figure 3). C3 plants, covering a range of high marsh species have low $\delta^{13} \mathrm{C}$ values between -24 and $-30 \%$ while even within species, the ubiquitous $F$. rubra specimen $\delta^{13} \mathrm{C}$ values vary spatially across the marshes, with a mean of $-29.7 \pm 1.3 \%$. $\mathrm{C}_{4} S$. anglica plants from IMN and $\mathrm{QN}$ are enriched in ${ }^{13} \mathrm{C}$ relative to $\mathrm{C}_{3}$ plants from the region, with values of $-13.6 \pm 0.9 \%$. $\mathrm{C} / \mathrm{N}$ values exhibit large variation of between 9 and 23 for the 
different taxa, with a large variation for S. anglica, possibly due to roots sampled alongside leaves (Flood 2010).

Water sample stable isotope values $(-25.1 \pm 2.1 \%$ ) were variable across sites. Isotopic ratios of POM show a $6 \%$ decline in $\delta^{13} \mathrm{C}$ values from $-23.2 \%$ to $-29.1 \%$ as proximity to the River Shannon increases (Figure 3). Temporal variability also occurs, with the sample nearest the mouth of the estuary exhibiting variation of up to $1.7 \%$ across the time-scale sampled. $\mathrm{C} / \mathrm{N}$ ratios are low compared to the vegetation, with mean values $8.0 \pm 0.6$. There is reduced spatial variability in $\mathrm{C} / \mathrm{N}$ between samples compared to temporal variation which is present evidenced by the large error bars at each location.

\section{Approximate position of Figure 3}

For the sediment, there is a variation in both $\delta^{13} \mathrm{C}$ and $\mathrm{C} / \mathrm{N}$ across the sites (Figure 4). $S$. anglica is largely absent at RMN and $\delta^{13} \mathrm{C}$ variation here is only $4.4 \%$ across the site, with a linear $\mathrm{C} / \mathrm{N}$ increase of about 4 with altitude. Maximum $\delta^{13} \mathrm{C}$ variation of $9.4 \%$ is larger at QN, with enriched values from the tidal flats beneath MHWNT, up to terrestrial environments above HAT. C/N also displays a linear increase with altitude, rising from $<10$ on the tidal flats beneath mean MHWNT, to a maximum of 12.5 in the high marsh.

\section{Approximate position of Figure 4}




\section{Application of SIAR}

For these saltmarsh sediment sites, variation of $\delta^{13} \mathrm{C}$ and $\mathrm{C} / \mathrm{N}$ indicates vertical mixing of organic matter sources with a liner decrease in $\delta^{13} \mathrm{C}$ and an increase in $\mathrm{C} / \mathrm{N}$ with altitude.

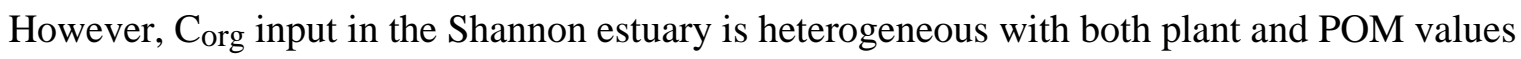
varying spatially and POM values also varying temporally. Reliable mixing model calculations hinge on the suitability of source values selected and values chosen from the Shannon are summarised in Table 2 with all sample and source values illustrated in Figure 5a. Traditional ternary end-member mixing models cannot incorporate with this heterogeneity and point values must be ascribed. For comparison, the mean values of these Shannon sources were used to calculate source contribution via the traditional method outlined in Liu and Kao (2007). As SIAR allows for source variability, mean and standard deviation can be used and its application should provide increased confidence in model output. The programme was run with 500,000 iterations using the reported sample and source values (below). Source values, relevant environmental variables, and modal solutions of source contribution together with $68 \%$ credibility intervals are presented in Figure $5 \mathrm{~b}$.

POM values are taken from mean water values at the respective sites and are similar to published values (Wilson et al. 2005a; Lamb et al. 2006). $\delta^{13} \mathrm{C}$ variation is set at that found during analysis $( \pm 0.75 \%$ at $\mathrm{RMN}$ and $\pm 0.54 \%$ at $\mathrm{QN})$. $\mathrm{C} / \mathrm{N}$ values are low, but show variation with 7.2 \pm 1.7 at $\mathrm{RMN}$ and $7.9 \pm 1.85$ and $\mathrm{QN}$. Due to the refractory nature of POM, diagenetic fractionation is minimal and ascribed a fractionation value of $0.0 \pm 0.5 \%$ and 
$0.0 \pm 0.5$ for $\delta^{13} \mathrm{C}$ and $\mathrm{C} / \mathrm{N}$ respectively. While this is similar to published values (Fogel et al.

Marsh $\mathrm{C}_{3}$ plant $\delta^{13} \mathrm{C}$ end-member values come from samples collected at their respective marshes (-26.7 $\pm 1.2 \%$ and $-28.5 \pm 0.8 \%$ o for $\mathrm{RMN}$ and $\mathrm{QN}$ respectively), while $\mathrm{C} 4$ plant endmember values, comprising of just Spartina anglica and showing reduced variability are the mean value of plants from the region $(13.58 \pm 0.85 \%$ ) which correspond to published mean values (-13.1\%o in Yu et al. (2010)) and standard deviation (Wilson et al. 2005b; Kemp et al. 2010). Previous studies have found minimal changes to surface bulk sediment $\delta^{13} \mathrm{C}$ values from degradation of plant biomass in marshes (e.g. Benner et al. 1987; Fogel \& Tuross 1999; Wilson et al. 2005b). To reflect this, no diagenetic fractionation has been ascribed, although an increased standard deviation of $0.0 \pm 1.0 \%$ has been introduced for prudence.

\section{Approximate position of Table 2}

There is a large variation in $\mathrm{C} / \mathrm{N}$ values of $\mathrm{C}_{3}$ and $\mathrm{C}_{4}$ plants, reflecting differences in cellulose composition and relative abundances of leaves to stems and roots. In an attempt to reduce this variation, $\mathrm{C}_{3}$ and $\mathrm{C}_{4}$ plant $\mathrm{C} / \mathrm{N}$ values are taken from the highest terrestrial sediment sample, above HAT at each site, where POM would not be deposited. Using this value, rather than that from individual plants, incorporates all factors that would affect plant $\mathrm{C} / \mathrm{N}$, including species variation, leaf/ root/ stem relative contributions, and diagenetic fractionation. While SIAR has the capability of including effects of diagenesis into calculations, this has not been fully quantified for $\mathrm{C} / \mathrm{N}$ on saltmarshes and as large diagenetic fractionations in this ratio 
have been reported previously (e.g. Chmura et al. 1987; Kemp et al. 2010), this is a useful area to quantify in the future. Given this uncertainty, it is more prudent to use an integrated signal of terrestrial soil $\mathrm{C} / \mathrm{N}$, than attempt to elucidate diagenetic changes to measured plant component. A conservative source variation estimate of \pm 2.0 is included to reflect the increased uncertainty of these values. As $\mathrm{C} / \mathrm{N}$ values have been estimated for sediment rather than plant values, no further degradation is expected but an additional fractionation term of $0.0 \pm 0.5$ is introduced.

\section{Approximate position of Figure 5}

A major advantage of SIAR over the traditional mixing model is in its calculation of credibility intervals. While the traditional method provides only one contribution value, SIAR's inclusion of credibility intervals allows for the assessment of confidence in the modal value. In both RMN and QN, given the difference in $\mathrm{C} / \mathrm{N}$ ratios and (particularly) $\delta^{13} \mathrm{C}$ values of $\mathrm{C}_{4}$ plants from the other two sources, the credibility intervals are reduced and more weight may be given towards the calculated contribution. In contrast, POM and $\mathrm{C}_{3}$ plants have more similar $\mathrm{C} / \mathrm{N}$ ratios and $\delta^{13} \mathrm{C}$ values, and credibility intervals are larger for these calculated contributions. These differences are not picked up using the traditional method.

There is similarity between the source contribution calculated both via SIAR and the traditional method. Many of the values calculated in the traditional method fall within the error estimates of SIAR, with some exceptions; though increasing the credibility interval to $95 \%$ would include more of the traditionally-calculated point values. However, traditional 
end-member source calculation failed to produce estimates for several of the higher-elevation stations at RMN, due to sediment values falling outside of the mixing triangle of sources (but within natural variability of the sources). To correct this, different source point values would have to be used (e.g. the outer extreme of mean plus standard deviation) and fractional contributions recalculated for the whole dataset. This is not ideal, and this problem is avoided using SIAR, as source variability is included and can be objectively set prior to model initiation; though attention should still be given to the possibility of samples falling outside the mixing triangle as SIAR will always calculate a value.

\title{
Corg distribution
}

Accurate quantification of source inputs allows determination of underlying processes within varied systems. While QN and RMN are spatially distributed within the Shannon estuary, with different floral characteristics, similarities do exist. MHWNT delineates the lower limit of marsh environments and at both these sites POM contribution declines above this level (Figure 6), in keeping with the expected correlation of POM deposition with tidal inundation (Wilson et al. 2005b) indicating confidence in the SIAR output.

\author{
At both sites, the decrease in POM deposition is concomitant with an increase in plant \\ biomass and SIAR predicts differences in the type of biomass deposited. MHWNT and \\ MHWST delineate the lower and upper extent of the low marsh, and in Ireland this \\ environment is dominated by the $\mathrm{C}_{4}$ plant $S$. anglica. For this environment, SIAR estimates
}


low $\mathrm{C}_{4}$ input at $\mathrm{RMN}$, while $\mathrm{QN}$ is identified as having a larger $\mathrm{C}_{4}$ contribution. These predictions are supported by the field evidence of a reduced S. anglica presence at RMN, and an extensive one at QN.

\section{Approximate position of Figure 6}

While the overall model framework of a subsiding marsh is corroborated by this SIAR output, some anomalies do occur. QN experiences contributions from POM and $\mathrm{C}_{4}$ material deposited above MHWST. This is unexpected as samples from these altitudes would experience decreased tidal inundation and therefore reduced deposition of these sources. Saltmarsh morphologies vary and QN marsh situated within a lagoon system, while RMN is open to the main estuary (Curtis \& Sheehy Skeffington 1998). It is possible the lagoon morphology results in changes to $\mathrm{C}_{\text {org }}$ deposition, with higher $\mathrm{C}_{4}$ plant debris and POM becoming concentrated and deposited at high elevations during flood tides. Alternatively, additional, currently unaccounted for $\mathrm{C}_{\text {org }}$ sources may be depositing on QN. One advantage of SIAR is that it is capable of modelling greater than three sources for sediment using $\delta^{13} \mathrm{C}$ and C/N (see Semmens et al. 2013 for discussion), and future work could incorporate these (e.g. CAM plants, agricultural organic inputs, freshwater algae or other $\mathrm{C}_{3}$ macrophytes). 


\section{Discussion}

Quantification of fractional contribution of heterogeneous sources to a mixed sample using SIAR is a significant improvement over traditional mixing models. Including error propagation into mixing model calculations increases the strength of arguments that are based on the relative contributions of sources and can help understand the fundamental processes that control source mixing in any given system. In this study, strong inter-marsh source input variation is observed and the subtle intra-marsh altitudinal trends in Corg input is recorded using SIAR using $\delta^{13} \mathrm{C}$ and $\mathrm{C} / \mathrm{N}$ as system tracers.

However, care should be taken in constraining system tracer parameters. While SIAR offers increased resolution and the ability to quantify input variation, more work must be done to improve understanding of the studied system. Source parameters should be accurately and precisely determined to reflect meaningful contributions to sediment as this will result in increased accuracy and precision in determining fractional contributions. For example, in this study, agricultural organic matter sources could be quantified and better refinement of existing sources conducted, with both plant leaves and roots analysed to investigate potential differences in their deposition. Increased understanding of the diagenetic fractionation occurring on saltmarshes should also be sought. The strength of SIAR is that it has the potential to incorporate the previously considered hindrances of source variability and diagenesis in mixing model calculations. As a result of the incorporation of error, further inferences can be made on a system. 


\section{Relative sea-level application}

To illustrate this point, one relative sea level (RSL) application will be outlined as an example of the possible benefits of using more complex mixing models in geochemical studies. Recently conducted, geochemically-based RSL studies with global applications would potentially benefit from this kind of modelling approach that quantifies source $\mathrm{C}_{\text {org }}$ input (Wilson et al. 2005b; Lamb et al. 2007; Da Cruz Miranda et al. 2009; Castro et al. 2010; Kemp et al. 2010; Khan et al. 2015). In these studies, trends of $\delta^{13} \mathrm{C}$ and $\mathrm{C} / \mathrm{N}$ across saltmarshes have been used to infer changes in relative sea-level through the Holocene by differentiating between altitudinally controlled organic matter source and the extent of geochemical variations across marshes is used to interpret RSL changes. However, saltmarsh organic geochemical values vary between marshes due to varying source inputs, marsh morphology and diagenetic fractionation, so studies are generally site-, or region-specific. To complicate matters, in the UK and Ireland, the composition of contemporary marshes is distinctly different from Holocene marshes due to the recent introduction of Spartina spp. in the $19^{\text {th }}$ Century (Stapf 1913). This genus is now ubiquitous and modern analogues of Holocene saltmarshes rarely exist, with the result that Holocene geochemical variations can only be crudely estimated. In the development of a geochemical training set to investigate RSL change Khan et al (2015) were restricted to locations where Spartina spp. had not colonised, and potential sites were omitted. In these cases, if removal of $\mathrm{C}_{4}$ plant signature input was possible, compositional variations of Holocene saltmarshes could be better predicted. 
This issue can be addressed by producing robust estimates of source $\mathrm{C}_{\text {org }}$ contributions to modern marshes using SIAR and correcting for the modern occurrence of Spartina spp., or other known factors, by removing their contaminating effects. $\mathrm{C}_{4}$ plants out-compete $\mathrm{C}_{3}$ plants in the low marsh environment and in their absence $\mathrm{C}_{3}$ plants would occupy this niche. Thus, if $\mathrm{C}_{4}$ plants were not present at the sampled marshes, POM would decline in abundance with elevation, with a correlated increase in $\mathrm{C}_{3}$ plant contribution only.

Using the relative contributions of $C_{\text {org }}$ calculated via SIAR for the two marshes, it is possible to estimate isotopic values for sediment where the $\mathrm{C} 4$ source fraction has been replaced by a $\mathrm{C}_{3}$ signature. Thus the modal $\mathrm{C}_{4}$ contribution to sediment (Figure 6) has been replaced by the $\mathrm{C}_{3}$ source composition at its respective site (mean values in Table 2). To investigate robustness of this prediction method, mean $\mathrm{C}_{4}$ plant values were first input into their relative contributions and "predicted" compositions show close agreement to recorded compositions (Figure 7). Replacing $\mathrm{C}_{4}$ source values with $\mathrm{C}_{3}$ ones, sediment values were then predicted for a $\mathrm{C}_{3}$-only marsh and these are also illustrated in Figure 7. As identical $\mathrm{C} / \mathrm{N}$ source compositions for $\mathrm{C}_{3}$ and $\mathrm{C}_{4}$ plants were used in the SIAR calculations, these would not vary when corrected.

\section{Approximate position of Figure 7}

Predicted changes to $\mathrm{C} 3$-only marshes show a reduced range of $\delta^{13} \mathrm{C}$ values, retaining framework model predictions of vertical mixing. At RMN, this range $0.5 \%$, with $\delta^{13} \mathrm{Ca}$ values decreasing with elevation, while at QN this range is $2.4 \%$. The difference between 
these two ranges is due to the position within the larger estuary. RMN is situated within the inner estuary and would experience increased organic input from $\mathrm{C}_{3}$ terrestrial plants and freshwater POM originating from the River Shannon catchment. These have a more negative value than marine organic inputs (Figure 3) and at QN, increased proportion of marine organic carbon deposited at lower elevation explains the larger range.

Given the large error associated with determining fractional contributions of $\mathrm{C}_{\text {org }}$ to sediment (Figure 5), the use of mean "point" values of sources for the back calculation of Corg modal contributions, and potentially differential biomass contributions of $\mathrm{C}_{3}$ and $\mathrm{C}_{4}$ plants, these predicted isotope values should be interpreted with caution and used only as an estimate of marsh variability. However, this site-specific signal could still be sought in the sediment record to help identify Holocene saltmarshes: e.g. in RSL studies. In particular, it is seen that marshes expected to have experienced increased marine deposition signature should preserve a greater range in original $\delta^{13} \mathrm{C}$ values and would therefore have increased probability of elucidating information.

The mixing of isotopic and elemental signals from varied sources is a common feature in many geochemical studies: lead isotope ratios have been used to determine provenance of contaminant metals in rivers (Bird et al. 2010); carbon isotope ratios used to determine land use changes in estuaries (Rogers 2013); sulphur to trace organic matter flow (Peterson \& Howarth 1987). While in this study, SIAR has been applied to stable isotope ratio, this statistical package should also be applicable to studies incorporating elemental as well as 
stable isotopic tracers and may be an instructive and useful method that can be more widely applied in a geochemical context. Further work in this area could incorporate the full range of SIAR output estimates into additional analysis and interpretation of data: e.g. temporally changing proportional contributions of sources (see Parnell et al. 2013).

\section{Conclusion}

Mixing models using the sophisticated computational package SIAR that incorporates Bayesian error estimates can be applied to simulated data using $\delta^{13} \mathrm{C}$ and $\mathrm{C} / \mathrm{N}$ as system tracers to predict $C_{\text {org }}$ mixing and are a significant improvement over traditional end-member mixing models. Mixing proportions calculated by SIAR accurately estimated simulated $\mathrm{C}_{\text {org }}$ contribution from three sources, indicating that underlying assumptions of the SIAR model, based on relative ratio behaviour, are applicable in a geochemical context using absolute ratios. While the traditional method calculated source proportions, these varied greatly from true values with no indication of precision. The use of SIAR is not restricted to saltmarshes and should provide significant improvements in many mixing model applications.

Within subsiding saltmarshes, using both absolute- and relative-ratio system tracers, SIAR identified increasing plant biomass deposition with altitude, at the expense of POM, in keeping with model framework predictions. This pattern was identified at two disparate sites in the Shannon estuary with different morphologies and floral characteristics, and the model 
could correctly distinguish between high and low $\mathrm{C}_{4}$ input marsh. Credibility intervals for modal fractional $\mathrm{C}_{\text {org }}$ contribution can also be determined for each of the sources, providing significant improvements over traditional mixing models. By correctly identifying and quantifying source inputs and diagenetic fractionation there is great scope for incorporating these mixing model calculations within the field of geochemistry.

Using SIAR modal values, $\mathrm{C}_{4}$ contribution was removed and replaced with a $\mathrm{C}_{3}$ signature in these saltmarshes. This modelled value better reflects $\mathrm{C}_{3}$ Holocene saltmarsh geochemical gradients prior to the introduction of the $\mathrm{C}_{4}$ plant Spartina in the region. The inner estuary site exhibited a $0.5 \%$ variation in $\delta^{13} \mathrm{C}$, while the outer estuary site exhibited a $2.4 \%$ range. This variation could be targeted in $\mathrm{C}_{3}$ dominated Holocene cores for RSL reconstruction.

\section{Acknowledgements}

Funding for this work was provided through an IRCSET postgraduate scholarship award scheme and IAGC student grant. The authors wish to thank Kevin Healy and Andrew Jackson for early conversations on the use of elemental ratios with SIAR. Robbie Goodhue was as helpful as ever in the lab and Niamh O'Sullivan provided great support in the field. We are grateful to Andrew Jackson for comments and discussions. 


\section{References}

Andrews, J. E., Samways, G., Dennis, P. F. \& Maher, B. A. 2000: Origin, abundance and storage of organic carbon and sulphur in the Holocene Humber Estuary: emphasizing human impact on storage changes. Geological Society, London, Special Publications 166, 145-170.

Barlow, N. L. M., Long, A. J., Saher, M. H., Gehrels, W. R., Garnett, M. H. \& Scaife, R. G. 2014: Salt-marsh reconstructions of relative sea-level change in the North Atlantic during the last 2000 years. Quaternary Science Reviews 99, 1-16.

Benner, R., Fogel, M. L. \& Sprague, E. K. 1987: Depletion of ${ }^{13}$ C in lignin and its impications for stable carbon isotope studies. Nature 329, 708-710.

Benner, R., Fogel, M. L. \& Sprague, E. K. 1991: Diagenesis of Belowground Biomass of Spartina alterniflora in Salt-Marsh Sediments. Limnology and Oceanography 36, 1358-1374.

Bindoff, N. L., Willebrand, J., Artale, V., Caszenave, A., Gregory, J., Gulev, S., Hanawa, K., Le Quéré, C., Levitus, S., Nojiri, Y., Shum, C. K., Talley, L. D. \& Unnikrishnan, A. 2007: Observations: oceanic climate change and sea level. In Solomon, S., Qin, D., Manning, M., Chen, Z., Marquis, M., Averyt, K. B., Tignor, M. \& Miller, H. L. (eds.): Climate Change 2007: The Physical Science Basis: Contribution of Working Group I to the Fourth Assessment Report of the Intergovernmental Panel on Climate Change, 385-432 pp. CambridgeUniversity Press, Cambridge.

Bird, G., Brewer, P. A., Macklin, M. G., Nikolova, M., Kotsev, T., Mollov, M. \& Swain, C. 2010: Quantifying sediment-associated metal dispersal using $\mathrm{Pb}$ isotopes: Application of binary and multivariate mixing models at the catchment-scale. Environmental Pollution 158, 2158-2169.

Bradley, S. L., Milne, G. A., Shennan, I. \& Edwards, R. 2011: An improved Glacial Isostatic Adjustment model for the British Isles. Journal of Quaternary Science 26, 541-552.

Bradley, S. L., Milne, G. A., Teferle, F. N., Bingley, R. M. \& Orliac, E. J. 2009: Glacial isostatic adjustment of the British Isles: new constraints from GPS measurements of crustal motion. Geophysical Journal International 178, 14-22.

Brooks, A. J., Bradley, S. L., Edwards, R. J., Milne, G. A., Horton, B. \& Shennan, I. 2008: Postglacial relative sea-level observations from Ireland and their role in glacial rebound modelling. Journal of Quaternary Science 23, 175-192. 
Castro, D. F., Rossetti, D. d. F. \& Ruiz Pessenda, L. C. 2010: Facies, $\delta^{13} \mathrm{C}, \delta^{15} \mathrm{~N}$ and C/N analyses in a late Quaternary compound estuarine fill, northern Brazil and relation to sea level. Marine Geology 274, 135-150.

Chmura, G. L., Aharon, P., Socki, R. A. \& Abernethy, R. 1987: An Inventory of ${ }^{13}$ C Abundances in Coastal Wetlands of Louisiana, USA: Vegetation and Sediments. Oecologia 74, 264-271.

Church, J. A. \& White, N. J. 2011: Sea-Level Rise from the Late 19th to the Early 21st Century. Surveys in Geophysics 32, 585-602.

Craft, C. B., Broome, S. W., Seneca, E. D. \& Showers, W. J. 1988: Estimating sources of soil organic matter in natural and transplanted estuarine marshes using stable isotopes of carbon and nitrogen. Estuarine, Coastal and Shelf Science 26, 633-641.

Craven, K. F. 2013: Testing the utility of an organic geochemical approach to Holocene sea-level change in the Shannon estuary. Geology. University of Dublin, Dublin.

Craven, K. F., Edwards, R. J., Goodhue, R. \& Rocha, C. 2013: Evaluating the Influence of Selected Acid Pre-Treatment Methods on $\mathrm{C} / \mathrm{N}$ and $\delta^{13} \mathrm{C}$ of Temperate Inter-Tidal Sediments for Relative Sea Level Reconstruction. Irish Journal of Earth Sciences $31,25-42$.

Curtis, T. G. F. \& Sheehy Skeffington, M. J. 1998: The Salt Marshes of Ireland: An Inventory and Account of Their Geographical Variation. Biology and Environment: Proceedings of the Royal Irish Academy 98B, 87 -104.

Da Cruz Miranda, M. C., De Fátima Rossetti, D. \& Carlos Ruiz Pessenda, L. 2009: Quaternary paleoenvironments and relative sea-level changes in Marajó Island (Northern Brazil): Facies, $\delta^{13} \mathrm{C}, \quad \delta^{15} \mathrm{~N}$ and C/N. Palaeogeography, Palaeoclimatology, Palaeoecology 282, 19-31.

Edwards, R. J., van de Plassche, O., Gehrels, W. R. \& Wright, A. J. 2004: Assessing sealevel data from Connecticut, USA, using a foraminiferal transfer function for tide level. Marine Micropaleontology 51, 239-255.

Emery, K. O., Wigley, R. L., Bartlett, A. S., Rubin, M. \& Barghoorn, E. S. 1967: Freshwater Peat on the Continental Shelf. Science 158, 1301-1307.

Erhardt, E. B. 2010: SISUS: Stable Isotope Sourcing using Sampling. Date accessed: July 2014 July 2014. 
Flood, R. 2010: Stable isotope and microfossil analysis of the Fergus Estuary, Co. Clare, Ireland: An assessment of methodologies for relative sea-level reconstruction studies. Geography. University of Dublin, Dublin.

Fogel, M. L., Kent Sprague, E., Gize, A. P. \& Frey, R. W. 1989: Diagenesis of organic matter in georgia salt marshes. Estuarine, Coastal and Shelf Science 28, 211-230.

Fogel, M. L. \& Tuross, N. 1999: Transformation of Plant Biochemicals to Geological Macromolecules during Early Diagenesis. Oecologia 120, 336-346.

Gehrels, W. R., Callard, S. L., Moss, P. T., Marshall, W. A., Blaauw, M., Hunter, J., Milton, J. A. \& Garnett, M. H. 2012: Nineteenth and twentieth century sea-level changes in Tasmania and New Zealand. Earth and Planetary Science Letters 315-316, 94-102.

Goñi, M. A., Teixeira, M. J. \& Perkey, D. W. 2003: Sources and distribution of organic matter in a river-dominated estuary (Winyah Bay, SC, USA). Estuarine, Coastal and Shelf Science 57, 1023-1048.

Gordon, E. S. \& Goñi, M. A. 2003: Sources and distribution of terrigenous organic matter delivered by the Atchafalaya River to sediments in the northern Gulf of Mexico. Geochimica et Cosmochimica Acta 67, 2359-2375.

Hopkins, J. B., III \& Ferguson, J. M. 2012: Estimating the Diets of Animals Using Stable Isotopes and a Comprehensive Bayesian Mixing Model. PLoS ONE 7, e28478.

Jackson, A. L., Inger, R., Bearhop, S. \& Parnell, A. 2009: Erroneous behaviour of MixSIR, a recently published Bayesian isotope mixing model: a discussion of Moore \& Semmens (2008). Ecology Letters. Wiley-Blackwell.

Kemp, A. C., Horton, B. P., Donnelly, J. P., Mann, M. E., Vermeer, M. \& Rahmstorf, S. 2011: Climate related sea-level variations over the past two millennia. Proceedings of the National Academy of Sciences 108, 11017-11022.

Kemp, A. C., Vane, C. H., Horton, B. P. \& Culver, S. J. 2010: Stable carbon isotopes as potential sea-level indicators in salt marshes, North Carolina, USA. Holocene 20, 623-636.

Khan, N. S., Vane, C. H., Horton, B. P., Hillier, C., Riding, J. B. \& Kendrick, C. P. 2015: The application of $\delta 13 \mathrm{C}$, TOC and $\mathrm{C} / \mathrm{N}$ geochemistry to reconstruct Holocene relative sea levels and paleoenvironments in the Thames Estuary, UK. Journal of Quaternary Science 30, 417-433.

Lamb, A. L., Vane, C. H., Wilson, G. P., Rees, J. G. \& Moss-Hayes, V. L. 2007: Assessing $\delta^{13} \mathrm{C}$ and $\mathrm{C} / \mathrm{N}$ ratios from organic material in archived cores as Holocene sea level and 
palaeoenvironmental indicators in the Humber Estuary, UK. Marine Geology 244, 109-128.

Lamb, A. L., Wilson, G. P. \& Leng, M. J. 2006: A review of coastal palaeoclimate and relative sea-level reconstructions using $\delta^{13} \mathrm{C}$ and $\mathrm{C} / \mathrm{N}$ ratios in organic material. Earth-Science Reviews 75, 29-57.

Liu, K.-K. \& Kao, S.-J. 2007: A Three End-Member Mixing Model Based on Isotopic Composition and Elemental Ratio. Terrestrial, Atmospheric \& Oceanic Sciences 18, 1067-1075.

Mackie, E. A. V., Leng, M. J., Lloyd, J. M. \& Arrowsmith, C. 2005: Bulk organic $\delta^{13}$ C and $\mathrm{C} / \mathrm{N}$ ratios as palaeosalinity indicators within a Scottish isolation basin. Journal of Quaternary Science 20, 303-312.

Parnell, A. C., Inger, R., Bearhop, S. \& Jackson, A. L. 2010: Source Partitioning Using Stable Isotopes: Coping with Too Much Variation. PLoS ONE 5, e9672.

Parnell, A. C., Phillips, D. L., Bearhop, S., Semmens, B. X., Ward, E. J., Moore, J. W., Jackson, A. L., Grey, J., Kelly, D. J. \& Inger, R. 2013: Bayesian stable isotope mixing models. Environmetrics 24, 387-399.

Perdue, E. M. \& Koprivnjak, J.-F. 2007: Using the C/N ratio to estimate terrigenous inputs of organic matter to aquatic environments. Estuarine, Coastal and Shelf Science 73, $65-72$.

Peterson, B. J. \& Howarth, R. W. 1987: Sulfur, Carbon, and Nitrogen Isotopes Used to Trace Organic Matter Flow in the Salt-Marsh Estuaries of Sapelo Island, Georgia. Limnology and Oceanography 32, 1195-1213.

Phillips, D. L. 2001: Mixing Models in Analyses of Diet Using Multiple Stable Isotopes: A Critique. Oecologia 127, 166-170.

Phillips, D. L. \& Gregg, J. W. 2001: Uncertainty in source partitioning using stable isotopes. Oecologia 127, 171-179.

Phillips, D. L. \& Gregg, J. W. 2003: Source partitioning using stable isotopes: coping with too many sources. Oecologia 136, 261-269.

Phillips, D. L., Newsome, S. D. \& Gregg, J. W. 2005: Combining Sources in Stable Isotope Mixing Models: Alternative Methods. Oecologia 144, 520-527. 
Rogers, K. M. 2013: Using stable isotopes to detect land use change and nitrogen sources in aquatic systems. In IAEA (ed.): Application for Isotope Techniques for Assessing Nutrient Dynamics in River Basins, 235 pp. IAEA, Vienna.

Schultz, D. J. \& Calder, J. A. 1976: Organic carbon C/ C variations in estuarine sediments.

Semmens, B. X., Ward, E. J., Parnell, A. C., Phillips, D. L., Bearhop, S., Inger, R., Jackson, A. \& Moore, J. W. 2013: Statistical basis and outputs of stable isotope mixing models: Comment on Fry (2013). Marine Ecology Progress Series 490, 285-289.

Stapf, O. 1913: Townsend's grass or ricegrass. Proceedings of the Bournemouth Natural Science Society 5, 76-82.

Team, R. D. C. 2011: R: A Language and Environment for Statistical Computing. In Computing, R. F. f. S. (ed.). Vienna, Austria.

Törnqvist, T. E., Gonzalez, J. L., Newsom, L. A., van der Borg, K., de Jong, A. F. M. \& Kurnik, C. W. 2004: Deciphering Holocene sea-level history on the U.S. Gulf Coast: A high-resolution record from the Mississippi Delta. Geological Society of America Bulletin 116, 1026-1039.

Vane, C. H., Drage, T. C. \& Snape, C. E. 2006: Bark decay by the white-rot fungus Lentinula edodes: Polysaccharide loss, lignin resistance and the unmasking of suberin. International Biodeterioration \& Biodegradation 57, 14-23.

Wilson, G. P., Lamb, A. L., Leng, M. J., Gonzalez, S. \& Huddart, D. 2005a: $\delta^{13}$ C and C/N as potential coastal palaeoenvironmental indicators in the Mersey Estuary, UK. Quaternary Science Reviews 24, 2015-2029.

Wilson, G. P., Lamb, A. L., Leng, M. J., Gonzalez, S. \& Huddart, D. 2005b: Variability of organic $\delta^{13} \mathrm{C}$ and $\mathrm{C} / \mathrm{N}$ in the Mersey Estuary, U.K. and its implications for sea-level reconstruction studies. Estuarine, Coastal and Shelf Science 64, 685-698.

Yu, F., Zong, Y., Lloyd, J. M., Huang, G., Leng, M. J., Kendrick, C., Lamb, A. L. \& Yim, W. W. S. 2010: Bulk organic $\delta^{13} \mathrm{C}$ and $\mathrm{C} / \mathrm{N}$ as indicators for sediment sources in the Pearl River delta and estuary, southern China. Estuarine, Coastal and Shelf Science 87, 618-630. 
Tables

Table 1: Simulated source compositions of common saltmarsh organic matter (OM) sources. C/N is provided for illustration only; N/C is used for all model calculations. S1-S3 refer to sources 1-3 respectively.

\begin{tabular}{cccc}
\hline System Tracer & POM & C4 OM & C3 OM \\
& $\left(\mathbf{s}_{1}\right)$ & $\left(\mathbf{s}_{2}\right)$ & $\left(\mathbf{s}_{3}\right)$ \\
\hline$\delta^{15} \mathrm{C}(\%)$ & $-26.00 \pm 1.00$ & $-14.00 \pm 1.00$ & $-28.00 \pm 1.00$ \\
$\mathrm{C} / \mathrm{N}$ & $8 \pm 2.00$ & $13 \pm 2.00$ & $15 \pm 2.00$ \\
& Diagenetic fractionation factor & \\
$\delta^{13} \mathrm{C}(\%)$ & $0.00 \pm 0.00$ & $0.00 \pm 0.00$ & $0.00 \pm 0.00$ \\
$\mathrm{C} / \mathrm{N}$ & $0.0 \pm 0.0$ & $0.0 \pm 0.0$ & $0.0 \pm 0.0$ \\
\hline
\end{tabular}

Table 2: Isotopic and elemental compositions of OM sources to saltmarsh sites used for SIAR calculations with additional diagenetic fractionation to source compositions. $\mathrm{C} / \mathrm{N}$ is provided for illustration only; N/C is used for all model calculations.

\begin{tabular}{ccccc}
\hline Site & Source & $\boldsymbol{\delta}^{\mathbf{1 3}} \mathbf{C ~ ( \% o )}$ & $\mathbf{n}$ & $\mathbf{C} / \mathbf{N}$ \\
\hline RMN & POM & $-25.46 \pm 0.75$ & 3 & $7.2 \pm 1.7$ \\
& C4 Plants & $-13.58 \pm 0.85$ & 4 & $12.4 \pm 2.0$ \\
& C3 Plants & $-26.72 \pm 1.20$ & 7 & $12.4 \pm 2.0$ \\
QN & POM & $-23.79 \pm 0.54$ & 3 & $7.9 \pm 1.9$ \\
& C4 Plants & $-13.58 \pm 0.85$ & 4 & $12.4 \pm 2.0$ \\
& C3 Plants & $-28.46 \pm 0.80$ & 8 & $12.4 \pm 2.0$ \\
\hline & Diagenetic fractionation factor at both sites & - & $0.0 \pm 0.5$ \\
& POM & $0.00 \pm 0.50$ & - & $0.0 \pm 0.5$ \\
& C4 Plants & $0.00 \pm 1.00$ & - & $0.0 \pm 0.5$ \\
\hline
\end{tabular}


A
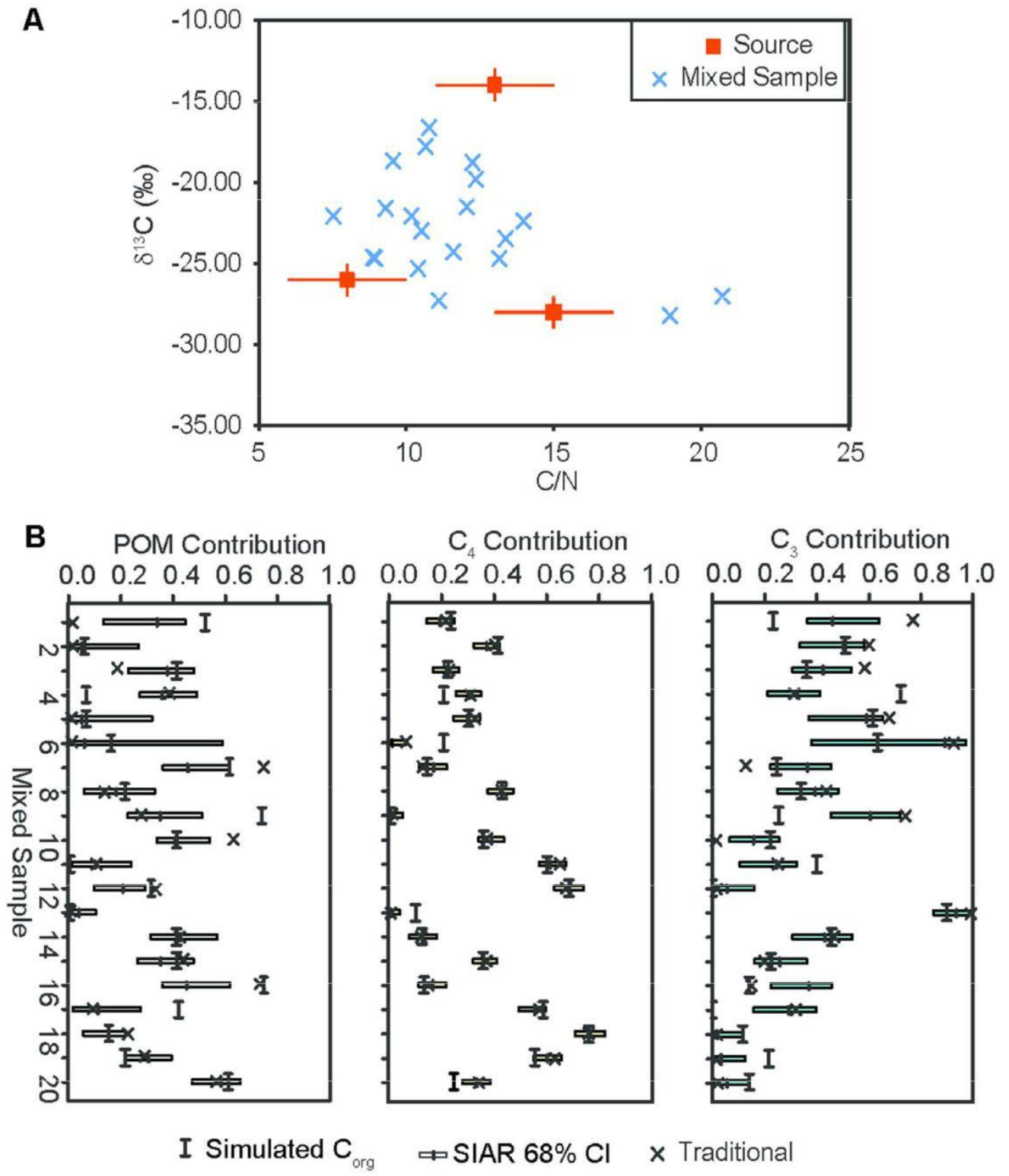

Figure 1: A) $\delta 13 \mathrm{C}$ and $\mathrm{C} / \mathrm{N}$ of simulated mixed samples together with sources. Error bars indicate \pm 1 s.d. of sources. B) End-member fractional contribution of POM, C4 and C3 as calculated by: traditional ternary endmember equations (black crosses); SIAR mode and $68 \%$ CI predictions of Corg contributions (small vertical bar with coloured box); and simulated, "true" Corg proportion (large vertical bar). Figure 1

$$
90 \times 107 \mathrm{~mm}(300 \times 300 \mathrm{DPI})
$$


Figure 2: A) Study area within Ireland. B) Locations of water samples (dashed lines) and sites sampled for plants (filled circles) through the Shannon estuary. Distances for water samples are from tidal limit of the Shannon estuary, with one freshwater sample (not shown) taken $12 \mathrm{~km}$ upriver of tidal limit. Numbers refer to saltmarshes: 1-Ringmoylan (RMN); 2-Inishmacnaghtan (IMN); 3-Islandavanna; 4- Aughinish; 5-Knock; 6-Carrigafoyle; 7Moyasta; 8-Blackweir Bridge (BWB); 9-Querrin (QN); 10-Carrigaholt. C) \& D) Sample sites within the Shannon estuary showing sediment transects.

Figure 2

$147 \times 153 \mathrm{~mm}(300 \times 300 \mathrm{DPI})$ 

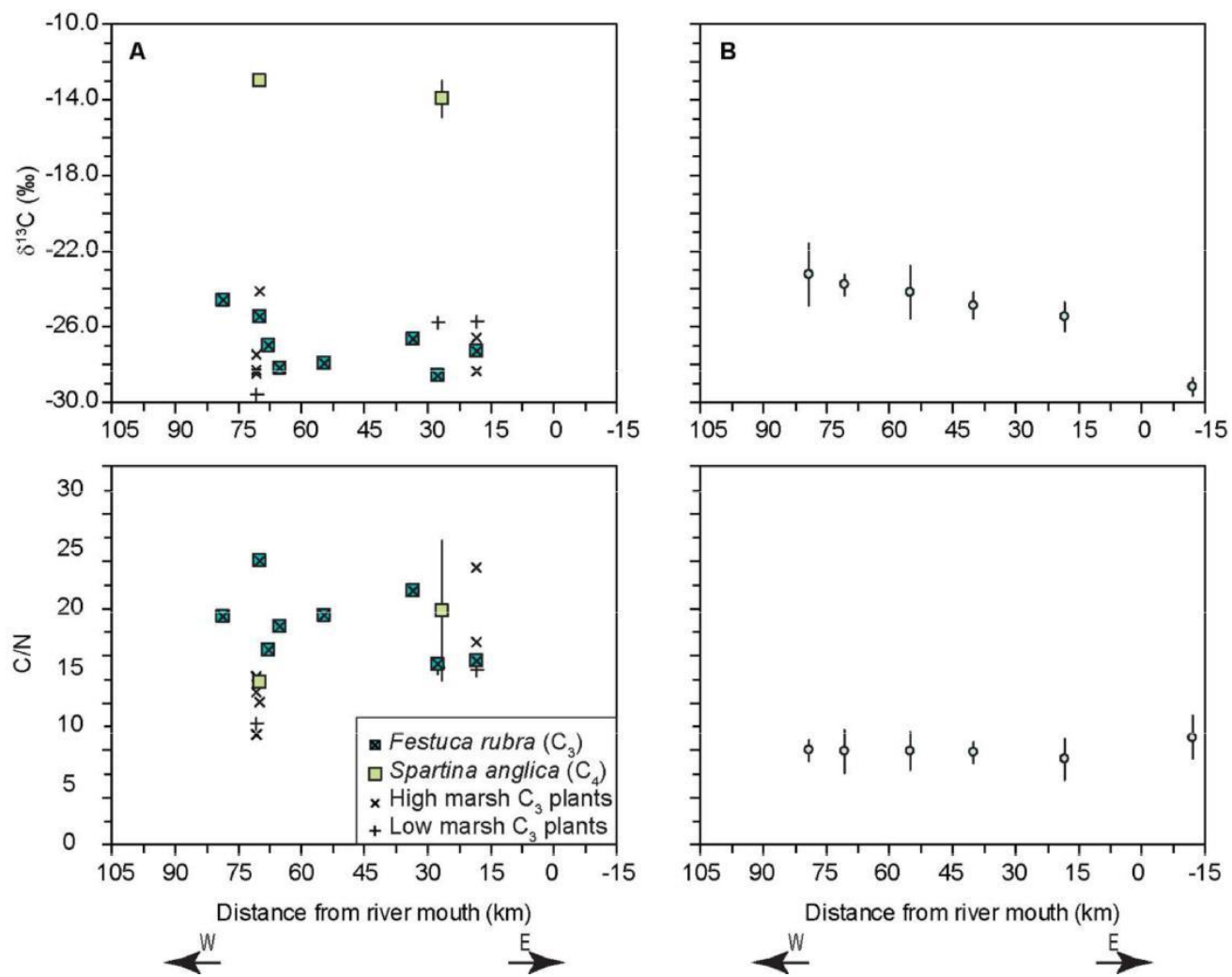

Figure 3: Isotopic values and $\mathrm{C} / \mathrm{N}$ ratios of $\mathrm{A}$ ) individual plant species and $\mathrm{B}$ ) temporal average POM of water samples (Plants: Festuca rubra, cross in square; Spartina anglica, open square; C3 high marsh plants, cross; C3 low marsh plants, plus; error bars are \pm 1 s.d. where larger than symbol). Water samples: mean values of high and low tides from August 2009, April 2010 and June 2010; error bars are \pm 1 s.d.). Distances measured from mouth of the River Shannon. Figure 3 


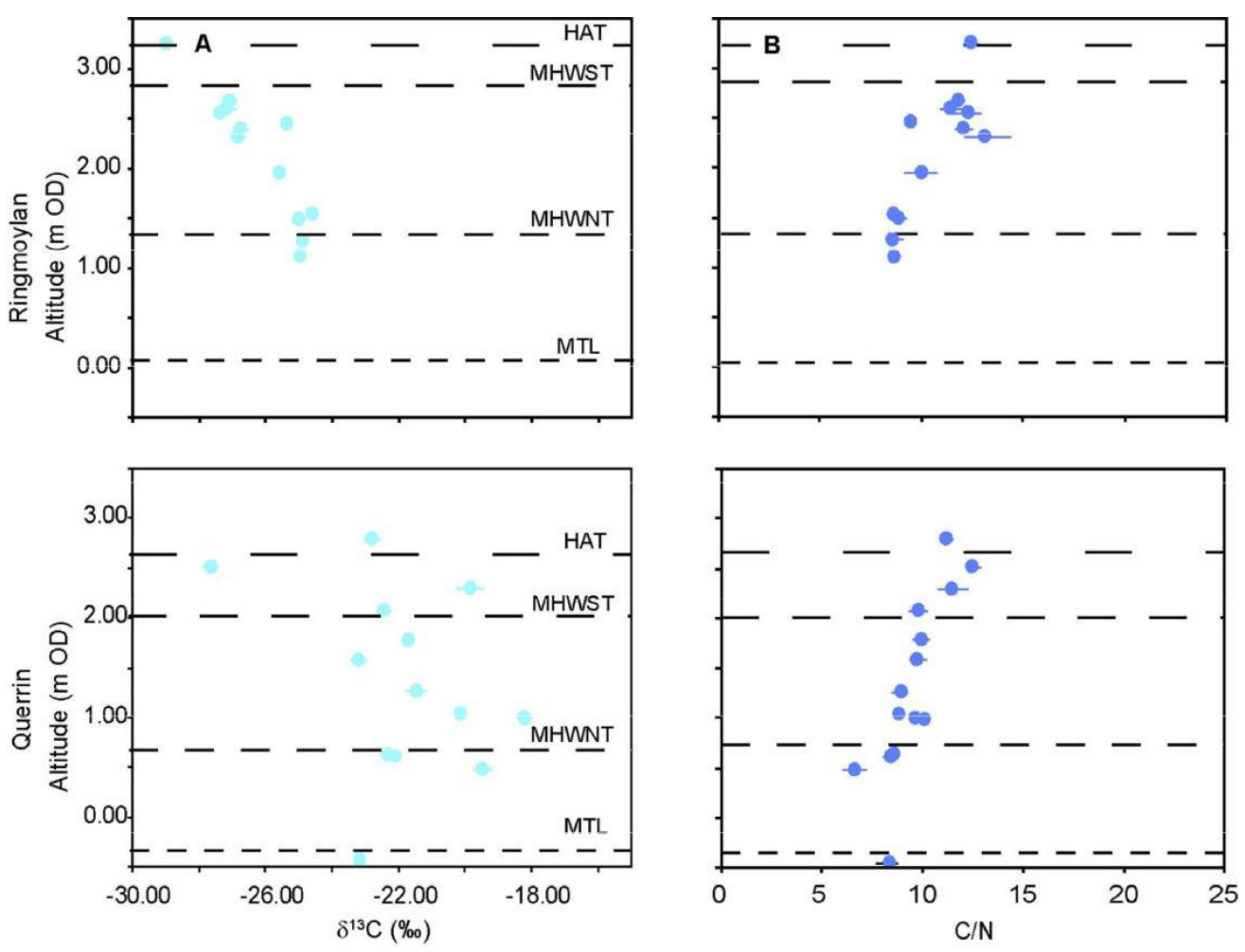

Figure 4: $\delta 13 C$ values $(A)$ and $C / N$ ratios $(B)$ of surface sediment from the two saltmarshes of this study. Error bars are \pm 1 s.d. Figure 4 $140 \times 105 \mathrm{~mm}(300 \times 300 \mathrm{DPI})$ 

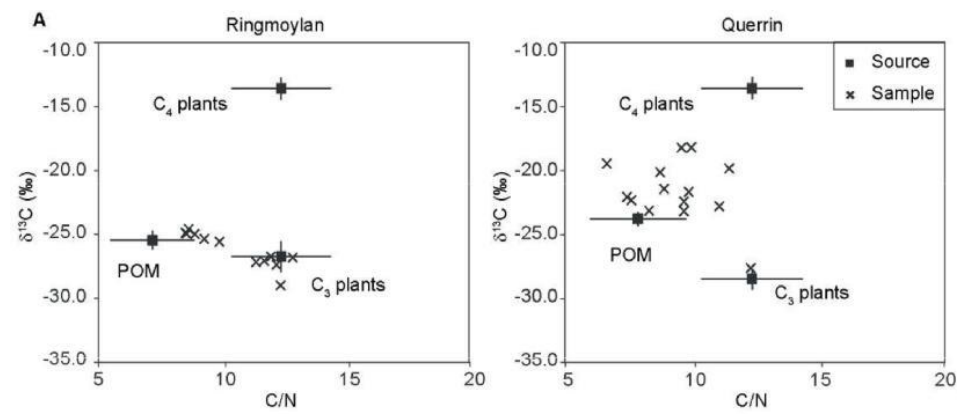

B

$\mathrm{C}_{4}$ Contribution

$\mathrm{C}_{3}$ Contribution

$\begin{array}{lllllllllllllll}0.00 & 0.25 & 0.50 & 0.75 & 1.00 & 0.00 & 0.25 & 0.50 & 0.75 & 1.00 & 0.00 & 0.25 & 0.50 & 0.75 & 1.00\end{array}$
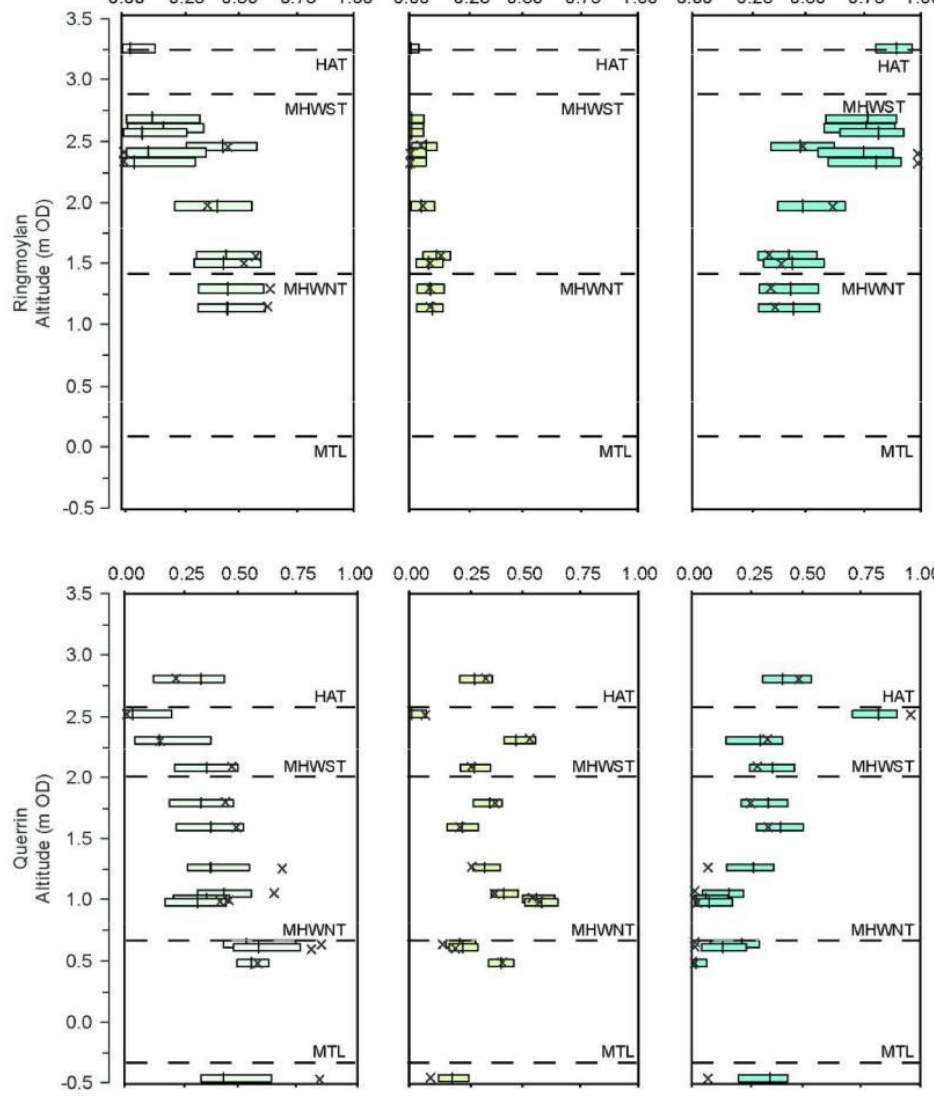

Figure 5: A) Carbon biplots of $\delta 13 \mathrm{C}$ and $\mathrm{C} / \mathrm{N}$ of sediment and source values from A) RMN, B) QN used during SIAR computations of mixing models. Error bars indicate estimated \pm 1 s.d. of source composition. B)

Calculated source fractional contribution of POM, C3 plants and C4 plants to sediment at RMN and QN. Black lines indicate modal contributions with coloured boxes representing $68 \%$ credibility interval. Black crosses are source fractional contribution as calculated using traditional ternary end-member mixing model of Liu and Kao (2007); calculated values $<0.00$ or $>1.00$ are not shown (top four stations of RMN). Dashed lines show tidal reference levels (defined in text).

Figure 5

$143 \times 236 \mathrm{~mm}(300 \times 300$ DPI $)$ 


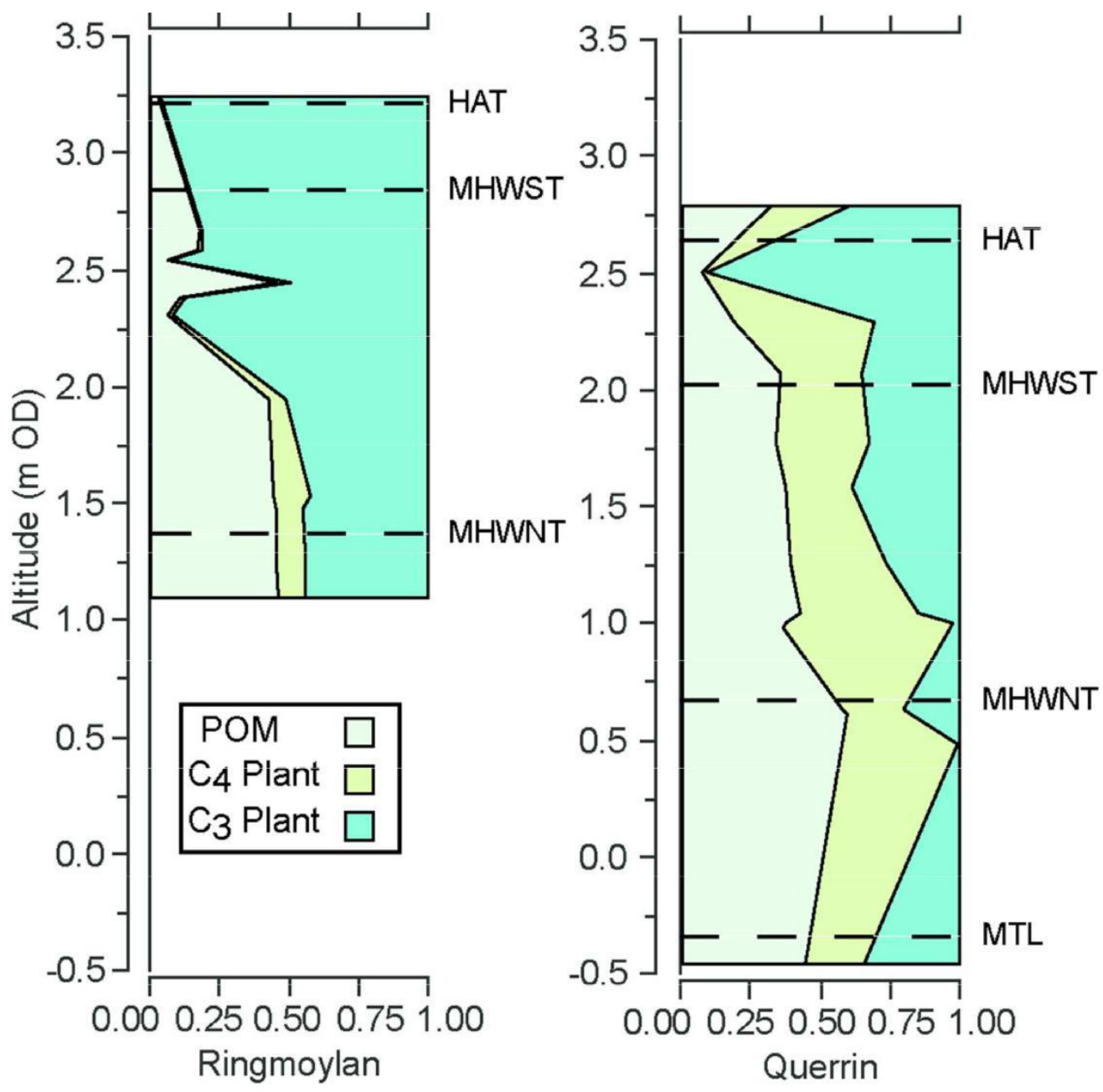

Figure 6: Modal Corg fractional contribution to saltmarshes relative to altitude based on ternary endmember SIAR mixing model with 500000 iterations. POM refers to annually integrated POM signal. C4 and C3 Plant refer to fractional contribution of Corg derived from C4 and C3 plants. Figure 6 


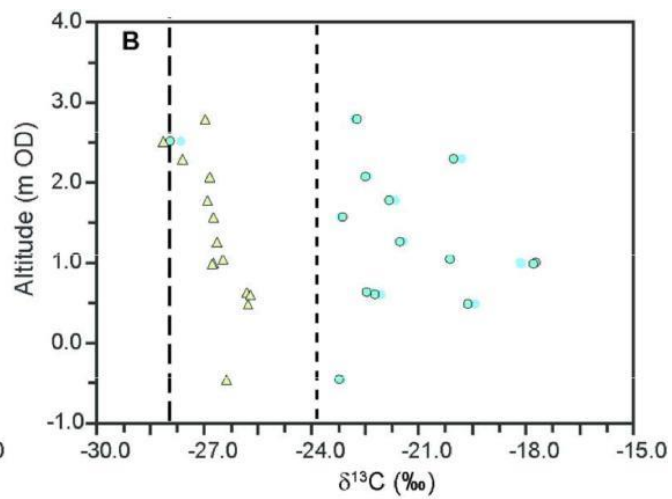

Figure 7: $\delta 13 \mathrm{C}$ values of sediment from: A) RMN and B) QN. Closed circles are measured values; open circles are modelled values using mean SIAR source values and modal proportions; open triangles are modelled values as above, replacing C4 plant component with C3 values. C3 plant and POM source values at each site are shown, C4 source value was $-13.58 \%$.

$143 \times 54 \mathrm{~mm}(300 \times 300$ DPI $)$ 